\title{
Serum C-peptide level correlates with the course of muscle tissue healing in the rabbit model of critical limb ischemia
}

\author{
Zdenek Tauber ${ }^{{ }^{*}}$, Katerina Cizkova ${ }^{a, b}{ }^{*}$, Maria Janikovac, ${ }^{, d}$, Jana Jurcikova ${ }^{e}$, Katerina Vitkovae, Lubomir Pavliskae, \\ Ludmila Porubova', Agata Krauze ${ }^{g}$, Carlos Fernandez ${ }^{9}$, Frantisek Jaluvka", Iveta Spackova', Ivo Lochman', Martin Prochazkac, \\ Brian H. Johnstone", Vaclav Prochazka'
}

\begin{abstract}
Aim. The therapeutic potential of adipose-derived stem cell conditioned medium (ASC-CM) was studied in the rabbit model of critical limb ischemia (CLI).

Methods. Rabbits received treatment with ASC-CM or placebo. Gastrocnemius muscle tissue was collected 35 days after ischemia induction. Ischemic changes were evaluated in hematoxylin-eosin stained tissues for early (necrotic lesions/granulation tissue) and late (fibrous scars) phases of tissue repair. The expression of proangiogenic miR-126 was also evaluated using in situ hybridization. The levels of cytokines, insulin, and C-peptide were measured in blood. Results. Early repair phases were observed more often in placebo-treated samples (45.5\%) than in ASC-CM-treated ones (22.2\%). However, the difference was not statistically significant. We demonstrated a statistically significant positive correlation between the early healing phases in tissue samples and C-peptide levels in peripheral blood. The expression of proangiogenic miR-126 was also shown in a number of structures in all phases of ischemic tissue healing. Conclusion. Based on our results, we believe that treatment with ASC-CM has the potential to accelerate the healing process in ischemic tissues in the rabbit model of CLI. The whole healing process was accompanied by miR-126 tissue expression. C-peptide could be used to monitor the course of the tissue healing process.
\end{abstract}

Key words: mesenchymal stem cells, tissue healing, cytokines, C-peptide, miR-126, critical limb ischemia

Received: March 11, 2018; Accepted with revision: August 17, 2018; Available online: September 7, 2018 https://doi.org/10.5507/bp.2018.048

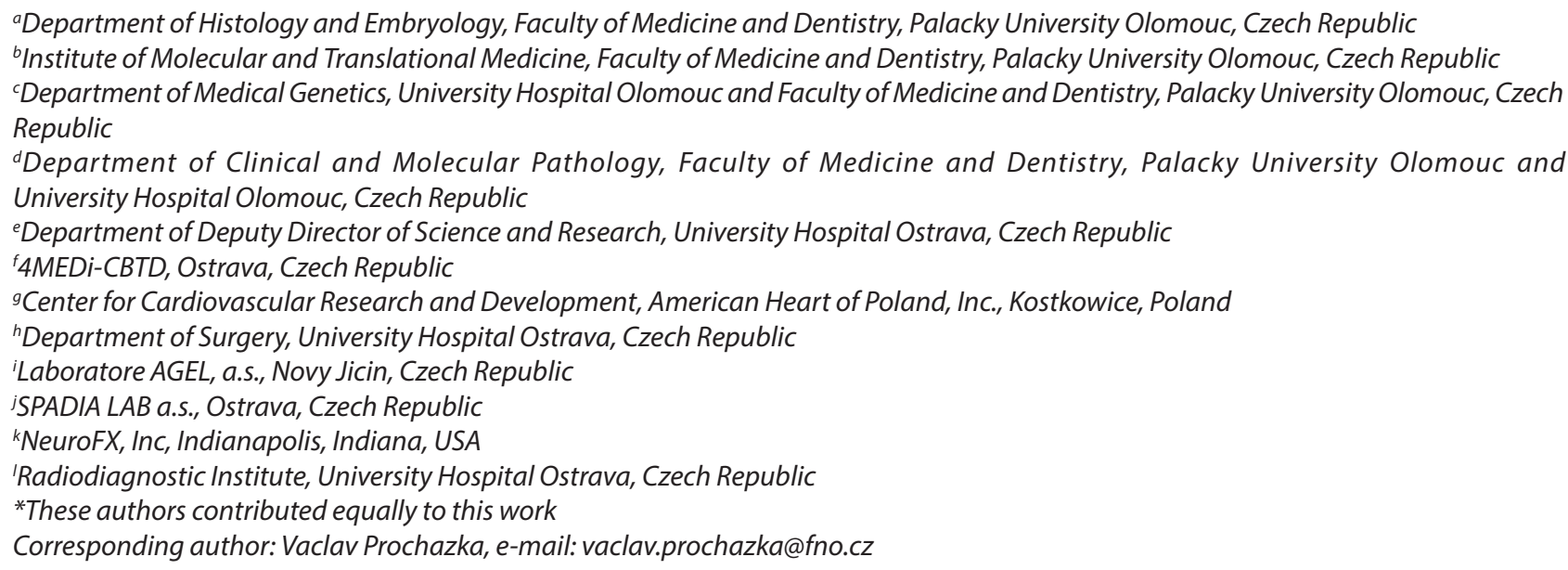

\section{INTRODUCTION}

Wound healing is a complex series of events that occur through the intricately coordinated actions and timing of many different processes. Wound healing is categorized into four sequential and overlapping phases: (1) haemostasis; (2) inflammation; (3) proliferation; and (4) remodelling. Immediately following injury, the haemostasis phase begins with vascular constriction, platelet aggregation, and clot formation. This leads to the inflammation phases in which immune and inflammatory cells are recruited to the wound bed and bacteria are cleared. Overlapping the inflammation phase is the proliferation phase. During this phase, there is extensive cell proliferation and migra- tion to the wound bed. Re-epithelialization, angiogenesis, and production of granulation tissue occur. In the last phase, remodelling, the extracellular matrix is remodelled and contracted by myofibroblasts to close the wound ${ }^{1-5}$. Diabetic foot ulceration (DFU) is a major health problem, with considerable morbidity and mortality along with a heavy financial burden for health care ${ }^{6}$. Although neuropathy, vascular disease, and trauma are the main factors leading to the development of DFU, impaired wound healing is the main issue leading to the development of chronic wounds and lower extremity amputations ${ }^{7}$.

In our previous study ${ }^{8}$, we demonstrated in the rabbit model of critical limb ischemia that adipose-derived stem cell-conditioned medium (ASC-CM) can accelerate neo- 
vascularization and significantly improve ischemic tissue reperfusion.

Human adipose tissue contains a population of mesenchymal stem cells intimately associated with blood vessels ${ }^{9}$. These adipose-derived stem cells (ASC) can be harvested in relatively high numbers using minimally invasive techniques of lipoaspiration or lipectomy ${ }^{9,10}$. Transplantation of ASC is an emerging therapeutic option for addressing many intractable diseases, including cardiovascular conditions such as peripheral arterial disease ${ }^{10-15}$. Evidence suggests that the therapeutic effects of ASC are primarily mediated through paracrine mechanisms rather than through cellular transdifferentiation ${ }^{16-19}$. These secreted factors can be captured in conditioned medium (ASC-CM) comprised of a cocktail of beneficial growth factors and cytokines that both individually and in combination demonstrate disease-modifying effects in animal models ${ }^{20}$.

The three predominant paracrine actions of stem cellsecreted factors are: (1) trophic support of survival and repair of cells in diseased or injured tissues (VEGF, HGF); (2) modulation of the immune system (IL-10, PGE2); and (3) recruitment of endogenous stem and progenitor cells (GM-CSF, SDF-1). These factors have the potential to work in concert to affect physiological improvements in diseased and injured tissues ${ }^{19}$.

The miR-126 is often referred to in the literature as an endothelium-specific proangiogenic microRNA and is recognized as the most important miRNA for maintaining vascular integrity during ongoing angiogenesis because it targets SPRED1 and PIK3R2, two negative regulators of VEGF and FGF signalling. Endothelial miR-126 can regulate both features of angiogenesis as well as vasculogenesis, suggesting a role for miR-126 in the maintenance of endothelial homeostasis ${ }^{21-23}$.

This study addresses the relationship between ASCCM treatment, diabetes induced in rabbits, serum levels of selected proteins and the rate of healing of ischemic muscle tissue. The rabbit tissues in the ischemic region were analysed for miR-126 expression. The rabbit model of critical limb ischemia was used under both normal and induced diabetic conditions.

\section{MATERIALS AND METHODS}

\section{Human and animal research approvals}

The collection of adipose tissue from donors was performed on the basis of informed consent. All procedures involving animals were approved by the Local Ethics Committee of the Polish Academy of Science, Kraków, Poland (approval no. 1103/2014).

\section{ASC isolation, ASC-CM preparation, and characteristics}

Adipose tissue was obtained from a single male patient ( 40 years of age, BMI $54 \mathrm{~kg} / \mathrm{m}^{2}$ ) undergoing elective lipoplasty. The tissue was processed for stromal vascular fraction (SVF) isolation using a Cytori Celution device as described previously ${ }^{8}$. Preparation and characterization of ASC-CM was performed as in the previous study ${ }^{8}$. The characteristics of cell populations from freshly obtained SVF and cultured ASCs are shown in Table 1. The concentration of selected proteins in human ASC-CM used for treatment of rabbits is shown in Table 2.

\section{Animals}

A total of 50 female New Zealand White Rabbits were purchased from Zakład Doświadczalny Instytutu Zootechniki PIB, Chorzelów, Poland. The environmental controls on temperature and humidity were set per the Centre for Cardiovascular Research and Development (Kostkowice, Poland) standards for animal care. Animals were acclimated to the test facility for at least 14 days prior to the start of the study. A standard diet was provided and water ad libitum. Each rabbit had a unique ID number (ear tag + tattoo). Body weights were recorded on arrival at the facility and weekly thereafter until the end of the experiment. The most recent body weight was used to calculate all perioperative medications. Body temperature was measured using a rectal probe thermometer. For the pilot study, 3 rabbits were used to test critical limb ischemia development and 47 rabbits were included in the treatment group. Of this group, 12 rabbits died during the experiment. Thus, 35 rabbits were available for the final analyses.

Table 1. Characterization of cell population of freshly obtained SVF and cultured ASC at passages 3 (P3) and 5 (P5) using a flow cytometric technique ${ }^{8}$.

\begin{tabular}{ccccc}
\hline CD markers & Fresh SVF, $\%$ & CD markers & P3 ASC, $\%$ & P5 ASC, \% \\
\hline CD34+/CD10+ & 2 & CD34-/CD10+ & 38 & 28 \\
CD34+/CD13+ & 90 & CD34-/CD13+ & 100 & 99 \\
CD34+/CD14+ & 5 & CD34-/CD14+ & 0 & 0 \\
CD34+/CD29+ & 100 & CD34-/CD29+ & 98 & 96 \\
CD34+/CD31+ & 61 & CD34-/CD31+ & 1 & 2 \\
CD34+/CD45+ & 3.5 & CD34-/CD45+ & 0.5 & 0.2 \\
CD34+/CD49+ & 42 & CD34-/CD49+ & 2 & 3 \\
CD34+/CD73+ & 100 & CD34-/CD73+ & 94 & 84 \\
CD34+/CD105+ & 100 & CD34-/CD105+ & 87 & 88 \\
\hline
\end{tabular}


Table 2. Concentrations of selected protein levels in 50-fold concentrated TFC (huTFC) and in human serum (huSerum) from a healthy donor. All values are expressed as $\mathrm{pg} / \mathrm{ml}\left(\right.$ ref. $\left.^{8}\right)$.

\begin{tabular}{lcc}
\hline Cytokine & huTFC & huSerum \\
\hline IFN $\gamma$ & $<10.0^{\mathrm{a}}$ & $<10.0^{\mathrm{a}}$ \\
IL-10 & $<3.0$ & $<3.0$ \\
IL-12 p70 & $<1.0$ & $<1.0$ \\
IL-13 & 4.9 & 10.1 \\
IL-1 $\beta$ & $<2.0$ & 2.6 \\
IL-2 & $<5.0$ & $<5.0$ \\
IL-4 & 5.0 & 0.9 \\
IL-6 & 369.0 & 3.0 \\
IL-7 & 0.2 & 41.2 \\
IL-8 & 36.8 & 2.2 \\
MMP-9 & 271.0 & $15,602.0$ \\
TNF $\alpha$ & 131.0 & 130.0 \\
aFGF & 439.0 & 2541.0 \\
IGF-I & $<0.1$ & $<0.1$ \\
PDGF-AA & 159.0 & $12,530.0$ \\
TGF- $\beta 1$ & 4296.0 & $13,924.0$ \\
VEGF & 7731.0 & 186.0 \\
\hline
\end{tabular}

a The "<" indicates a value below the detection limit

\section{Pre-treatment procedure and hind limb ischemia induction}

On Day -21 , diabetes was induced in rabbits in all experimental groups by an alloxan infusion $(130 \mathrm{mg} / \mathrm{kg}$, Sigma-Aldrich). After treatment, glucose-containing water was given to all rabbits for $48 \mathrm{~h}$ to prevent hypoglycaemia. After stabilization, the animal's blood glucose level was monitored weekly (a total of 8 samples between days -21 and 28). Rabbits with a blood glucose level greater than $10 \mathrm{mmol} / \mathrm{L}$ measured on day -14 of the experiment (i.e., 7 days after the induction of diabetes) were considered diabetic. On day -7 , the rabbits were anesthetized with an intramuscular injection of $20-40 \mathrm{mg} / \mathrm{kg}$, IM ketamine (Bioketan $100 \mathrm{mg} / \mathrm{mL}$, Vetoquinol, Gorzów Wielkopolski, Poland) and 5-10 mg/kg xylazine (Xylapan $20 \mathrm{mg} / \mathrm{mL}$, Vetoquinol, Gorzów Wielkopolski Poland) and a subcutaneous injection of $0.5 \mathrm{mg} / \mathrm{kg}$ atropine (Atropinum Sulfuricum $1 \mathrm{mg} / \mathrm{mL}$, Warszawskie Zakłady
Farmaceutyczne Polfa, Warszawa, Poland). Additional boluses of 20-50 mg IV (0.2-0.5 mL) ketamine were administered to maintain the proper depth of anaesthesia during surgical hind limb ischemia creation. The femoral artery and its branches as well as the femoral vein were ligated, beginning from the inguinal ligament to the bifurcation of the saphenous and popliteal arteries, and excised. The incision was closed with stainless steel staples.

\section{Study groups and treatment}

Rabbits with induced limb ischemia ( $n=35)$ were randomly assigned to the following five treatment groups: (1) Sham, (2) placebo intramuscularly (IM) (2 mL of Dulbecco's Modified Eagle's Medium [DMEM]), (3) ASC-CM IM (2 mL), (4) ASC-CM IM + intravenously (IV) (4 mL), (5) placebo IV, (2 mL of DMEM), and (6) ASC-CM IV (2 mL). Treatments were provided to animals on day 7 after surgery (Day 0 of the experiment). Rabbits with a normal blood glucose $<10 \mathrm{mmol} / \mathrm{L}$ were treated IM. The treatment administered IM was divided into 5 injection sites: two into each bundle of the gastrocnemius muscle (four injections) and one into the anterior tibial muscle. Rabbits with induced diabetes (blood glucose level $>10 \mathrm{mmol} / \mathrm{L}$ ) were treated IV. In the case of IV administration, the ear vein was injected. The treatment groups are shown in Table 3.

\section{Histology}

Tissue samples from the gastrocnemius muscle were collected on the last day of the experiment (Day 28; i.e., 35 days after induction of ischemia). Formol-fixed tissue segments were paraffin embedded and the blocks were sectioned at 2-4- $\mu$ m thicknesses and stained with hematoxylin-eosin (Merck, Kenilworth, NJ). Tissue samples were evaluated for the presence of necrotic areas, granulation tissue, and fibrous scars. Based on this evaluation, the samples were divided into the following groups: an early phase of healing (necrotic areas or granulation tissue), and a late phase of healing (fibrous scars).

\section{In situ hybridization (ISH)}

Sections with a thickness of 2-4 $\mu \mathrm{m}$ from the same paraffin blocks of gastrocnemius muscle were cut and placed on Superfrost Plus ${ }^{\circledR}$ slides (Thermo Scientific, Waltham, MA, USA). The ISH procedure was performed using the miRCURY LNA ${ }^{\mathrm{TM}}$ microRNA Detection

Table 3. Distribution of rabbits to the treatment groups.

\begin{tabular}{lcccc}
\hline $\begin{array}{l}\text { Treatment } \\
\text { groups }\end{array}$ & $\begin{array}{c}\text { No of rabbits included } \\
\text { in the experiment }\end{array}$ & $\begin{array}{c}\text { No of rabbits } \\
\text { analysed }\end{array}$ & $\begin{array}{c}\text { No of rabbits } \\
\text { deceased }\end{array}$ & Time of death \\
\hline Sham & 4 & 4 & 0 & $2 \times$ Day -7, 2 x Day+7 \\
Placebo IM & 9 & 5 & 4 & $3 \times$ Day-7, 1 x Day+7 \\
ASC-CM IM & 12 & 8 & 4 & Day-7 \\
ASC-CM IM-IV & 7 & 7 & 1 & $1 \times$ Day-7, 1 x Day 17, 1 x Day 28 \\
Placebo IV & 7 & 6 & 3 & 12 \\
ASC-CM IV & 8 & 5 & 35 & \\
\hline Total & 47 & &
\end{tabular}


Table 4. Blood glucose levels in diabetic rabbits over time.

\begin{tabular}{lccccccc}
\hline & Day -14 & Day -7 & Day 0 & Day 7 & Day 14 & Day 21 & Day 28 \\
\hline $\mathrm{n}$ & 13 & 8 & 6 & 9 & 5 & 5 & 5 \\
Range (mmol/L) & $10.99-30.25$ & $11.21-29.92$ & $11.49-25.76$ & $13.83-24.22$ & $19.21-28.42$ & $19.15-29.75$ & $12.93-33.31$ \\
Median (mmol/L) & 21.43 & 20.76 & 14.57 & 19.94 & 25.59 & 20.43 & 19.48 \\
\hline
\end{tabular}

Rabbits with hyperglycaemia greater than $10 \mathrm{mmol} / \mathrm{L}$ measured on Day -14 of the experiment (i.e., 7 days after the induction of diabetes) were considered diabetic $(\mathrm{n}=$ number of diabetic rabbits on each experiment day; the range and median of glycaemia are in $\mathrm{mmol} / \mathrm{L}$ ).

(FFPE) kit (90005, Exiqon, Vedbaek, Denmark) per the manufacturer's protocol. Proteinase K at a concentration of $0.5 \mu \mathrm{g} / \mathrm{mL}$ was applied to tissue sections for $10 \mathrm{~min}$ at $37^{\circ} \mathrm{C}$. The optimal probe concentration was established as $40 \mathrm{nM}$. Visualization of miR-126 was performed after hybridization with LNA probes included in the kit. Stained sections were assessed under an Olympus BX40 (Olympus, Tokyo, Japan) optical microscope.

\section{Analysis of serum protein levels}

Venous blood (4-5 mL) was collected from the auricular vein; serum was obtained and frozen for later use. Serum samples were analysed for multiple rabbit growth factors and cytokines by enzyme-linked immunosorbent assay, including the following: hepatocyte growth factor (HGF), granulocyte-macrophage colony-stimulating factor (GM-CSF), vascular endothelial growth factor (VEGF), basic-fibroblast growth factor (bFGF), glial cell-derived neurotrophic factor (GDNF), stromal cell-derived factor$1 \beta$ ( SDF-1 $\beta$ ), and transforming growth factor (TGF), (all kits were purchased from BlueGene Biotech, Shanghai, China) as well as insulin and C-peptide on Day -7 (induction of hind limb ischemia), Day 0 (treatment), Day 7 (one week after the treatment), and Day 28 (last day of the experiment).

\section{Data representation and statistical analyses}

The results were evaluated by the Mann-Whitney U test to compare the early and the late phases of wound healing for ASC-CM-treated and placebo-treated animals and between samples obtained from diabetic and nondiabetic rabbits. The same statistical analysis was performed to compare the serum levels of $\mathrm{C}$ peptide and tested growth factors and cytokines in samples with early phases and fully recovered rabbits (showing late phases) at the time of tissue collection (Day 28). A Spearman correlation was used to test the relationships of levels of growth factors, cytokines, insulin, and C peptide occurring during the early phases on Day 28.

The changes in the levels of cytokines and growth factors on Day 0, Day 7, and Day 28 in the placebo and treated groups and in the diabetic and nondiabetic groups were evaluated by the Kruskal-Wallis test. The level of significance was $P<0.05$. All calculations were performed with GraphPad Prism 6 software.

\section{RESULTS}

\section{Characterization of ASC-CM}

Characterization of ASC-CM was published ${ }^{8}$ and is summarized in Table 1. Levels of selected angiogenic and inflammatory cytokines and growth factors in 50fold concentrated TFC (therapeutic factor concentrate) were compared to human serum. These results were also published $^{8}$ and are shown in Table 2. While the concentrations of the majority of proteins were similar for TFC and human serum, the levels of VEGF, IL-6, and IL-8 were $>10$-fold higher in TFC than in serum. Conversely, levels of MMP9, IL-7, and PDGF-AA were much lower in TFC than in serum.

\section{Efficacy of alloxan-induced diabetes in the rabbit model}

Diabetes was induced in rabbits by alloxan infusion. The glucose levels were measured and rabbits with glucose levels $>10 \mathrm{mmol} / \mathrm{L}$ at day -14 ( 7 days after alloxan administration) were considered diabetic. The glucose levels were checked repeatedly every week (Day $-14,-7$, $0,7,14,21$, and 28). The number of diabetic rabbits, range of glucose levels, and medians obtained during each measurement are shown in Table 4.

\section{Histological evaluation of muscle tissue healing}

The incidence of early ischemic changes (presence of necrotic areas and granulation tissue) was demonstrated in $4 / 18(22.2 \%)$ samples treated with ASC-CM. In contrast, the incidence of early ischemic changes in the rabbit group treated with placebo was $5 / 11(45.5 \%)$. The difference between these two groups did not achieve statistical significance (Mann-Whitney test $P=0.24$ ). Interestingly, the incidence of early phases of tissue healing did not differ in groups with $(4 / 13,30.8 \%)$ or without $(5 / 16,31.3 \%)$ diabetes.

\section{Detection of miR-126 positivity with ISH}

The expression of miR-126 was demonstrated in a number of cellular elements of mesenchymal origin in both the early and the late phases of ischemic tissue healing. In samples with early phases of healing, miR-126 was found in the following structures: blood vessels (endothelium and smooth muscle cells), cellular elements of the granulation tissue, and in the necrotic but also regenerating muscle fibres. In the samples containing only late phase healing (i.e., fully recovered tissues), miR-126 posi- 


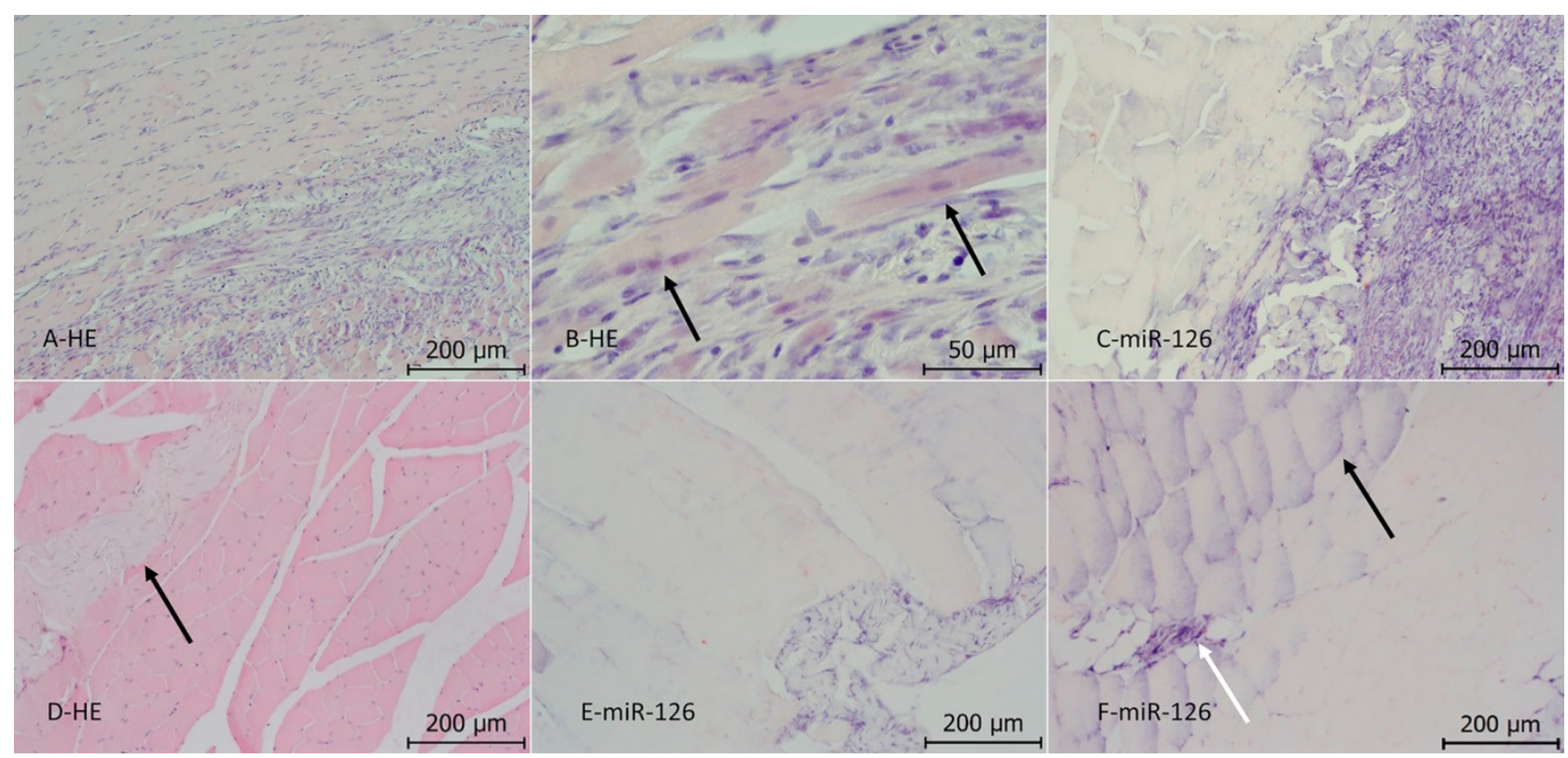

Fig. 1. Histological evaluation of the healing phases and miR-126 detection with in situ hybridization. (A) Early phases of healing with a necrotic field and granulation tissue (hematoxylin-eosin staining, magnification 100×). (B) Detail from the previous slide. Arrows show regenerating muscle tissue (magnification 400×). (C) miR-126 positivity detected with in situ hybridization in granulation tissue (magnification 100×). (D) Late phase of healing. Arrow indicates fibrous scar (magnification 100×). (E) miR-126 positivity in a fibrous scar (magnification 100×). (F) miR-126 positivity in vessels (white arrow) and regenerating muscle fibres (black arrow) (magnification 100×).

GM-CSF

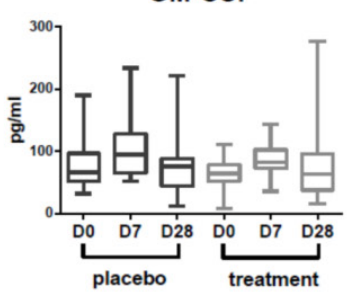

GDNF

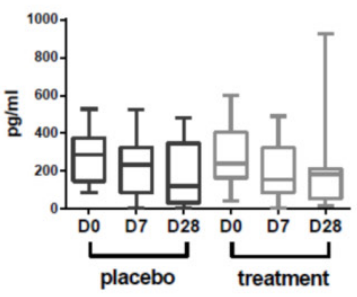

VEGF

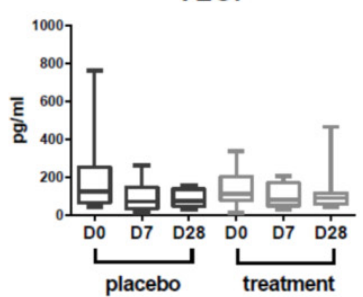

SDF-1b

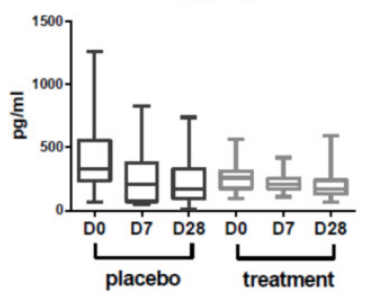

bFGF

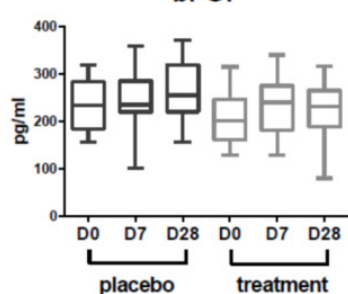

TGF

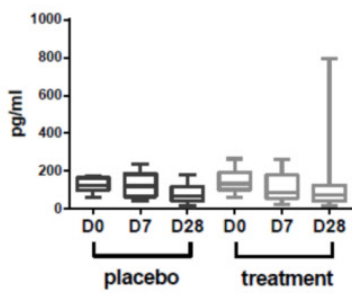

HGF

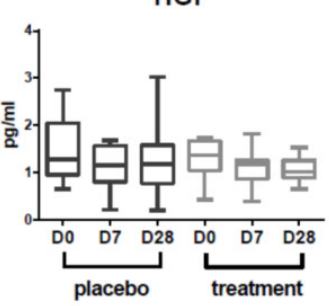

placebo

Fig. 2. Changes in the tested growth factor and cytokine levels on Days 0, 7, and 28 in serum of placebo-treated and ASC-CMtreated rabbits. There were no statistically significant differences.

tivity was found in the following structures: blood vessels (endothelium and smooth muscle cells), fibrous scars, and the sarcoplasm of regenerating muscle fibres (Fig. 1).

\section{Relationship between serum protein levels, treatment,} and the phases of tissue healing

In the course of this experiment, levels of growth factors and cytokines (GM-CSF, VEGF, HGF, bFGF, GDNF, SDF-1 $\beta$, and TGF) were monitored in the pe- ripheral blood at Days 0,7 , and 28. A comparison of the median serum levels of these growth factors and cytokines demonstrated no statistically significant difference between rabbits treated with ASC-CM versus placebo (Fig. 2) or between samples from diabetic and non-diabetic rabbits over the monitored time period (data not shown). The serum levels of these proteins and the histologically proven phases of ischemic tissue healing at the time of tissue collection (Day 28) are shown in 
GM-CSF

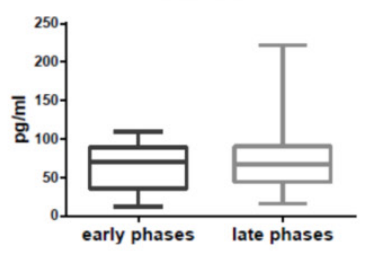

GDNF

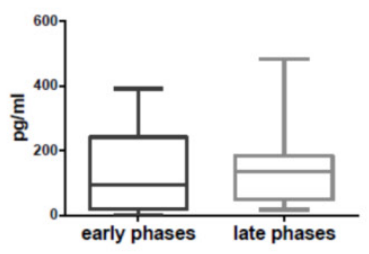

VEGF

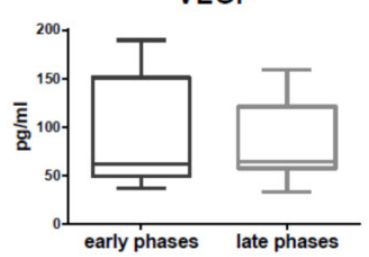

SDF-1b

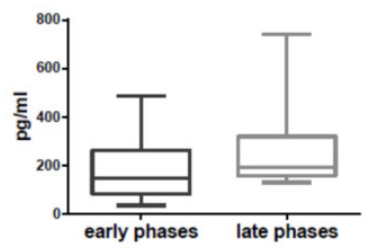

bFGF

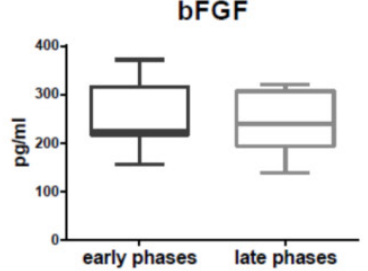

TGF

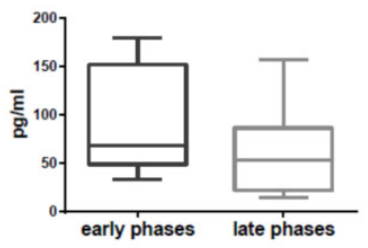

HGF

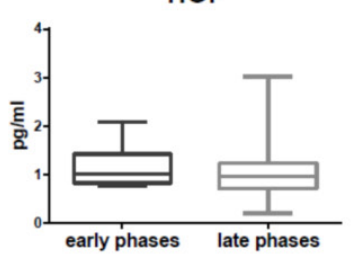

Fig. 3. Comparison of serum growth factor and cytokine levels in the early and late phases of tissue healing. There were no significant differences. Early phases represent necrotic areas and granulation tissue, whereas late phases represent fibrous scars.

\section{C-peptide}

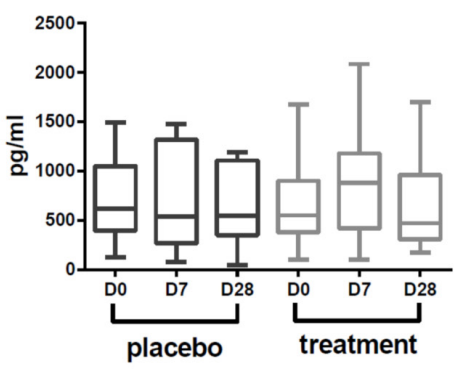

\section{C-peptide}

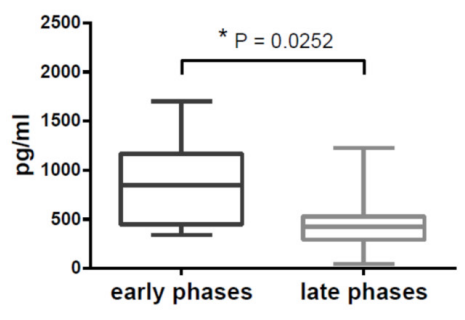

Fig. 4. Comparison of C-peptide levels during the early and late phases of tissue healing. We found statistically significant differences for C-peptide levels.

Fig. 3. There were no statistically significant differences between the groups. The insulin levels were comparable in the tested groups.

Interestingly, C-peptide serum levels were almost double in rabbits whose samples showed early phases of healing (median of $849.8 \mathrm{pg} / \mathrm{L}$ ) compared to those showing late phases of healing (median of $423.4 \mathrm{pg} / \mathrm{L}$ ) (Fig. 4). This difference was statistically significant $(P=0.025)$. In addition, the levels of C-peptide measured on the day of tissue collection (Day 28 of the experiment) correlated with the presence of the early healing phases (Spearman correlation test, $\mathrm{r}=0.488 ; P=0.021$ ). The $\mathrm{C}$-peptide levels on Days 0, 7, and 28 in the placebo- and ASC-CM-treated groups are also shown in Fig. 4.

\section{DISCUSSION}

This study addresses the relationship between ASCCM treatment, alloxan-induced diabetes, serum levels of selected proteins, and the rate of healing of ischemic muscle tissue. Moreover, we showed miR-126 expression. The rabbit model of critical limb ischemia was used under both normal and diabetic conditions.

Our study included rabbits with alloxan-induced diabetes and critical limb ischemia. The incidence of early phase tissue healing was comparable for groups with and without diabetes.

Alloxan-induced diabetes is a widely used model to induce type I diabetes mellitus in experimental animals. Alloxan has been found to be selectively toxic to pancreatic beta cells because it preferentially accumulates in these cells as glucose analogues. In addition, the cytotoxic action of alloxan is mediated mainly by the generation of 
reactive oxygen species. Alloxan and the product of its reduction, dialuric acid, establishes a redox cycle, with the formation of superoxide radicals that undergo dismutation to hydrogen peroxide $\left(\mathrm{H}_{2} \mathrm{O}_{2}\right)$ and other more highly reactive hydroxyl radicals are formed by the Fenton reaction. Furthermore, the massive increase in cytosolic calcium concentrations ultimately causes the rapid destruction of beta cells in pancreatic islets ${ }^{24-26}$. However, some authors have described limitations of the alloxan model. Alkizim et al. induced diabetes in rats with alloxan at a dose of $125 \mathrm{mg} / \mathrm{kg}$ IV Fasting blood glucose levels were assessed on Days $0,3,6,13,20$, and 27. Of 24 alloxan poisoned rats, only 10 were diabetic on day 27 . The authors concluded that induction of diabetes with alloxan in rats leads to variability in glucose levels, and that follow-up for at least one month is necessary before confirming the induction $^{26}$. Wang et al. successfully developed a long-term (over 12 months) rabbit model of diabetes. Alloxan was given IV at a dose of $100 \mathrm{mg} / \mathrm{kg}$. More than half of the experimental animals required a second injection of alloxan to maintain persistent hyperglycaemia (>300 mg/ $\mathrm{dL}$ ). To evaluate the effect of long-term diabetes on wound healing, they created full thickness skin wounds on the ventral surface of the pinnae in the experimental animals. In rabbits wounded two weeks following the induction of diabetes, the wound closure time tended to be longer ( 16.5 days) than in the age-matched nondiabetic rabbits (15.6 days), but the difference was not statistically significant $(P=0.3865)$. However, in rabbits that had been diabetic for one year, wound closure time (19.7 days) was significantly longer than in age-matched nondiabetic rabbits (15.1 days, $P<0.01$ ) (ref. ${ }^{25}$ ).

Under the conditions of our experiment, alloxan was administered as one intravenous injection in a dose of $130 \mathrm{mg} / \mathrm{kg}$. Even after successful diabetes induction, we observed significant fluctuations in blood glucose levels. At the end of our experiment (Day 28), only a minority of rabbits $(5 / 13)$ had blood glucose levels $>10 \mathrm{mmol} / \mathrm{L}$ and were diabetic. This fact clearly confirms the possible pitfalls of the alloxan model under experimental conditions and could explain why there was practically no difference in the rate of tissue healing (early/late phases) between diabetic and non-diabetic rabbits in our experiment. Therefore, we believe that the diabetic state of the rabbits in our experiment was far from that observed in diabetic patients in clinical practice.

In our previous study using the rabbit model of critical limb ischemia, we demonstrated that ASC-CM can accelerate neovascularization and significantly improve ischemic tissue reperfusion ${ }^{8}$. A possible mechanism of revascularization was the promotion of angiogenesis by the growth factors and cytokines in the ASC-CM-treated group. There are only sporadic reports about the possible relationship between the cytokine levels and the dynamics of tissue healing ${ }^{27-31}$.

In the study presented here, we demonstrate that the incidence of the early phases of healing in animals treated with ASC-CM was halved compared to animals treated with placebo. However, this difference was not statistically significant, probably due to the small sample size.
Based on these results, we believe that ASC-CM treatment has the potential to accelerate tissue healing in the rabbit model of critical limb ischemia.

Evidence suggests that the therapeutic effects of ASC are primarily mediated through paracrine mechanisms rather than cellular transdifferentiation ${ }^{16-19}$. The three predominant paracrine actions of stem cell-secreted factors are: (1) trophic support of survival and repair of cells in diseased or injured tissues; (2) modulation of the immune system; and (3) recruitment of endogenous stem and progenitor cells. Moreover, these factors have the potential to work in concert to affect physiological improvements in diseased and injured tissues ${ }^{19}$. These secreted factors can be captured in conditioned medium (ASC-CM) comprised of a cocktail of beneficial growth factors and cytokines that individually and in combination demonstrate disease-modifying effects in animal models ${ }^{20}$.

In the course of this experiment, the levels of GMCSF, VEGF, HGF, bFGF, GDNF, SDF-1 $\beta$, and TGF were monitored in peripheral blood (Days 0, 7, and 28). A comparison of median serum levels of these growth factors and cytokines demonstrated no statistically significant difference between ASC-CM-treated and placebotreated animals or between samples from diabetic and non-diabetic rabbits at any of these time periods. We failed to demonstrate a correlation between serum level of these proteins and histologically proven phases of ischemic muscle tissue healing at the time of tissue collection (Day 28).

Gohel et al evaluated the relationship between local (wound fluid) and systemic (venous) concentrations of IL-1, TNFalfa, VEGF, bFGF, and TGF-beta 1 and wound healing in patients with chronic venous ulceration. Ulcer healing correlated with increased concentrations of wound fluid TGF-beta1, possibly reflecting increased fibrogenesis in the proliferating wound. These authors did not demonstrate a correlation between serum levels of the cytokines observed and wound healing (assessed using digital planimetry). Aside from this, they also observed a large variation in wound and serum cytokine levels that largely limited their usefulness as markers of healing ${ }^{28}$. Murphy et al evaluated the local venous (superficial veins in the lower limb in the ulcer vicinity) levels of VEGF and TNF-alfa in limbs with venous ulcers before and after treatment with graduated compression. In patients with venous ulcers, there was a reduction in the levels of both cytokines to values that were below those of the control with treatment. These changes correlated with the healing of the ulcers as determined by a reduction in ulcer size $^{29}$. Dubsky et al assessed the levels of proangiogenic (VEGF, bFGF, Ang-1, and PDGF) and antiangiogenic (endostatin) factor levels in the venous blood of diabetic patients undergoing bone marrow or peripheral blood stem cell transplantation. No significant change in the serum levels of proangiogenic cytokines was observed 6 months after transplantation ${ }^{32}$. Based on our results as well as those of other authors, it seems difficult to monitor the tissue healing process based on systemic cytokine levels.

The miR-126 is often referred to in the literature as an 
endothelium-specific proangiogenic microRNA, and it is recognized as the most important miRNA for maintaining vascular integrity during ongoing angiogenesis. This is because it targets SPRED1 and PIK3R2, two negative regulators of VEGFs signalling ${ }^{21-23}$. Currently, there is no comprehensive description of miR-126 expression by ISH in ischemic skeletal muscle. We demonstrated miR-126 positivity in a number of cellular elements of mesenchymal origin in both the early and late phases of healing of ischemic muscle tissue. In addition to the positivity in newly formed vessels (endothelium and smooth muscle cells), we detected miR-126 positivity in the cellular elements of granulation tissue in the early phases of healing. In the late phases of healing, the positivity was evident in fibrous scars. Interestingly, miR-126 is present in the sarcoplasm of regenerating muscle fibres. Rissanen et al studied the expression of VEGF and VEGFR-2 in ischemic human and rabbit skeletal muscles with immunohistochemistry and ISH. In chronically ischemic human skeletal muscles, VEGF and VEGFR-2 expression was restricted to atrophic and regenerating skeletal myocytes, whereas in acutely ischemic limbs, VEGF and VEGFR-2 were expressed diffusely in the affected muscle. In the case of a rabbit model of critical limb ischemia, these authors demonstrated the expression of VEGF and VEGFR-2 in regenerating myotubes in samples taken one and three weeks after induction of ischemia. After six weeks, VEGF expression in muscle tissue was diminished. These authors suggested that VEGF may promote survival and regeneration of ischemic myocytes ${ }^{31}$. The findings of these authors are in concordance with our evidence of miR-126 positivity in the regenerating ischemic muscles, and support the assumptions about the possible complex role of miR-126 and VEGF in tissue homeostasis and reparative processes, including their possible role in repairing damaged muscle.

In addition to growth factors and cytokines, we also monitored serum levels of insulin and C-peptide in our study. As seen with growth factors and cytokines, there were no significant differences between the serum insulin levels and the treatment regimen, diabetes induction, or a relationship to the phases of tissue healing. Interestingly, we observed almost doubled C-peptide serum levels in rabbits whose samples contained the early phases of healing and this result was statistically significant $(P<0.05)$. In addition, the levels of C-peptide measured on the day of tissue collection (Day 28 of the experiment) correlated with findings from the early healing phases $(r=0.43$, $P<0.05)$. To our knowledge, this is the first description of such a relationship.

Proinsulin C-peptide is secreted into circulation in equimolar concentrations with insulin by pancreatic betacells. Compared to insulin, C-peptide has negligible extraction by the liver and constant peripheral clearance. Its half-life is longer than that of insulin (20-30 vs. 3-5 min) and it therefore circulates at concentrations that are approximately five times higher in the systemic circulation. C-peptide has emerged as a physiologically active peptide for ameliorating diabetes-induced complications including vascular dysfunction and inflammation ${ }^{33-35}$.
Lim et al. ${ }^{33}$ investigated the potential roles of C-peptide in protecting against impaired wound healing by inducing angiogenesis using streptozotocin-induced diabetic mice and human umbilical vein endothelial cells. C-peptide supplementation using osmotic pumps significantly increased the rate of skin wound closure in diabetic mice. Furthermore, C-peptide induced endothelial cell migration and tube formation in a dose-dependent manner ${ }^{33}$. In our study, the serum C-peptide level correlated with early phase healing (ongoing angiogenesis, granulation tissue). In the case of healed tissue (fibrous scars), we demonstrated significantly lower serum levels of C-peptide. Taken together, a high level of C-peptide is necessary in the early phases of healing (during ongoing angiogenesis and formation of granulation tissue), while in the later phases of healing (maturation of fibrous scars) it appears to be of less importance. Therefore, serum levels of the C-peptide could be a potential marker for monitoring the course of the tissue healing process because increasing level of C-peptide is representative of the intensive cellular and metabolic processes that are taking place in the early phases of healing.

Based on our results, we believe that ASC-CM treatment has the potential to accelerate tissue healing in a rabbit model of critical limb ischemia. We also demonstrated miR-126 positivity in a number of cellular elements of mesenchymal origin during both the early and late phases of healing of ischemic muscle tissue. Unfortunately, serum levels of growth factors and cytokines do not appear to be useful for monitoring the tissue healing process. On the other hand, serum C-peptide levels could be a potential marker for it. However, further studies are needed to confirm these findings.

\section{ABBREVIATIONS}

ASC-CM, Adipose-derived stem cell-conditioned medium; CLI, Critical limb ischemia; DFU, Diabetic foot ulceration; DMEM, Dulbecco's modified Eagle's medium ; IM, Intramuscularly; IV, Intravenously; mir-126, microRNA-126; SVF, Stromal vascular fraction; TFC, Therapeutic factor concentrate.

\section{Acknowledgement: We thank Ivana Travnickova and Lucie} Voznakova for technical support.

The work was supported in part by grants NPS I LO1304 and DRO (UP, 61989592) from the Czech Ministry of Education, Youth and Sports, Czech Republic, and the GESHER/MOST Program, project no. LJ14003 (DiaCellix - new regenerative medicine product for treatment of secondary effects of T2DM).

Author contributions: VP, BJ, JJ, KV, ZT: study design; MJ, KC, AK, CF, FJ, IS, IL, VP: data collection; LP, KC: statistical analysis; VP, BJ, MP, IL, MJ, ZT, KC, FJ: data interpretation; VP, BJ, MP, IL, LPa, MJ, ZT, KC, JJ, KV: contributed to the preparation of the manuscript; VP, ZT, $\mathrm{KC}, \mathrm{MJ}, \mathrm{IL}, \mathrm{MP}$ : literature search; VP, LPo, BJ, AK: secured the funding of the study. 
Conflict of interest statement: None declared.

Ethics approval and consent to participate: The collection of adipose tissue from donors was performed on the basis of informed consent. All procedures involving animals were approved by the Local Ethics Committee of the Polish Academy of Science, Kraków, Poland (approval no. 1103/2014).

\section{REFERENCES}

1. Guo S, Dipietro LA. Factors affecting wound healing. J Dent Res 2010 89(3):219-29.

2. Baum CL, Arpey CJ. Normal cutaneous wound healing: clinical correlation with cellular and molecular events. Dermatol Surg 2005;31(6):674-86.

3. Singer AJ, Clark RA. Cutaneous wound healing. N Engl J Med 1999;341(10):738-46.

4. Desmouliere A, Geinoz A, Gabbiani F, Gabbiani G. Transforming growth factor-beta 1 induces alpha-smooth muscle actin expression in granulation tissue myofibroblasts and in quiescent and growing cultured fibroblasts. J Cell Biol 1993;122(1):103-11.

5. Vyalov S, Desmouliere A, Gabbiani G. GM-CSF-induced granulation tissue formation: relationships between macrophage and myofibroblast accumulation. Virchows Archiv B Cell Pathol Incl Mol Patho 1993;63(4):231-9.

6. Ramsey SD, Newton K, Blough D, McCulloch DK, Sandhu N, Reiber $\mathrm{GE}$, Wagner $\mathrm{EH}$. Incidence, outcomes, and cost of foot ulcers in patients with diabetes. Diabetes Care 1999;22(3):382-7.

7. Falanga V. Wound healing and its impairment in the diabetic foot. Lancet 2005; 366(9498):1736-43.

8. Prochazka V, Jurcikova J, Lassak O, Vitkova K, Pavliska L, Porubova L, Buszman PP, Krauze A, Fernandez C, Jaluvka F, Spackova I, Lochman I, Jana D, Merfeld-Clauss S, March KL, Traktuev DO, Johnstone BN. Therapeutic Potential of Adipose-Derived Therapeutic Factor Concentrate for Treating Critical Limb Ischemia. Cell Transplant 2016;25(9):1623-33.

9. Traktuev DO, Merfeld-Clauss S, Li J, Kolonin M, Arap W, Pasqualini R, Johnstone BH, March KL. A population of multipotent CD34-positive adipose stromal cells share pericyte and mesenchymal surface markers, reside in a periendothelial location, and stabilize endothelia networks. Circ Res 2008;102(1):77-85.

10. Bourin P, Bunnell BA, Casteilla L, Dominici M, Katz AJ, March KL, Red $H$, Rubin JP, Yoshimura K, Gimble JM. Stromal cells from the adipose tissue-derived stromal vascular fraction and culture expanded adipose tissue-derived stromal/stem cells: a joint statement of the International Federation for Adipose Therapeutics and Science (IFATS) and the International Society for Cellular Therapy (ISCT). Cytotherapy 2013;15(6):641-8.

11. Miranville A, Heeschen C, Sengenes C, Curat CA, Busse R, Bouloumie A. Improvement of postnatal neovascularization by human adipose tissue-derived stem cells. Circulation 2004;110(3):349-55.

12. Moon MH, Kim SY, Kim YJ, Kim SJ, Lee JB, Bae YC, Sung SM, Jung JS. Human adipose tissue-derived mesenchymal stem cells improve postnatal neovascularization in a mouse model of hindlimb ischemia. Cellular Physiol Biochem 2006;17(5-6):279-90.

13. Bura A, Planat-Benard V, Bourin P, Silvestre JS, Gross F, Grolleau JL, Saint-Lebese B, Peyafitte JA, Fleury S, Gadelorge M, Taurand M, Dupuis-Coronas S, Leobon B, Casteilla L. Phase I trial: the use of autologous cultured adipose-derived stroma/stem cells to treat patients with non-revascularizable critical limb ischemia. Cytotherapy 2014;16(2):245-57.

14. Nakagami H, Maeda K, Morishita R, Iguchi S, Nishikawa T, Takami Y, Kikuchi Y, Saito Y, Tamai K, Ogihara T, Kaneda Y. Novel autologous cell therapy in ischemic limb disease through growth factor secretion by cultured adipose tissue-derived stromal cells. Arterioscler Thromb Vasc Biol 2005;25(12):2542-7.

15. Planat-Benard V, Silvestre JS, Cousin B, Andre M, Nibbelink M,
Tamarat R, Clergue M, Manneville C, Saillan-Barreau C, Duriez M, Tedgui A, Levy B, Penicaud L, Casteilla L. Plasticity of human adipose lineage cells toward endothelial cells: physiological and therapeutic perspectives. Circulation 2004;109(5):656-63.

16. Caplan Al, Dennis JE. Mesenchymal stem cells as trophic mediators. J Cell Biochem 2006;98(5):1076-84.

17. Gnecchi M, Zhang Z, Ni A, Dzau VJ. Paracrine mechanisms in adult stem cell signaling and therapy. Circ Res 2008;103(11):1204-19.

18. Kinnaird T, Stabile E, Burnett MS, Lee CW, Barr S, Fuchs S, Epstein SE. Marrow-derived stromal cells express genes encoding a broad spectrum of arteriogenic cytokines and promote in vitro and in vivo arteriogenesis through paracrine mechanisms. Circ Res 2004;94(5):678-85.

19. Murphy MB, Moncivais K, Caplan Al. Mesenchymal stem cells: environmentally responsive therapeutics for regenerative medicine. Exp Mol Med 2013;45:e54.

20. Bhang SH, Lee S, Shin JY, Lee TJ, Jang HK, Kim BS. Efficacious and clinically relevant conditioned medium of human adipose-derived stem cells for therapeutic angiogenesis. Mol Ther 2014;22(4):862-72.

21. Wang S, Aurora AB, Johnson BA, Qi X, McAnally J, Hill JA, Richardson JA, Bassel-Duby R, Olson EN. The endothelial-specific microRNA miR-126 governs vascular integrity and angiogenesis. Dev Cell 2008;15(2):261-71.

22. van Solingen $C$, Seghers $L$, Bijkerk R, Duijs JM, Roeten MK, van Oeveren-Rietdijk AM, Baelde HJ, Monge M, Vos JB, de Boer HC, Quax $\mathrm{PH}$, Rabelink TJ, van Zonneveld AJ. Antagomir-mediated silencing of endothelial cell specific microRNA-126 impairs ischemia-induced angiogenesis. J Cell Mol Med 2009;13(8A):1577-85.

23. Caporali A, Emanueli C. MicroRNAs in Postischemic Vascular Repair. Cardiol Res Pract 2012;2012:486702.

24. King AJ. The use of animal models in diabetes research. $\mathrm{Br} J$ Pharmacol 2012;166(3):877-94.

25. Wang J, Wan R, Mo Y, Zhang Q, Sherwood LC, Chien S. Creating a longterm diabetic rabbit model. Exp Diabetes Res 2010;2010:289614.

26. Alkizim FO, Kitua M, Matheka DM. Peculiar glycemic patterns in alloxaninduced diabetes animal model. Afr J Pharmacol Ther 2012;1(1):30-4

27. Beidler SK, Douillet CD, Berndt DF, Keagy BA, Rich PB, Marston WA. Inflammatory cytokine levels in chronic venous insufficiency ulcer tissue before and after compression therapy. J Vasc Surg 2009;49(4):1013-20.

28. Gohel MS, Windhaber RA, Tarlton JF, Whyman MR, Poskitt KR. The relationship between cytokine concentrations and wound healing in chronic venous ulceration. J Vasc Surg 2008;48(5):1272-7.

29. Murphy MA, Joyce WP, Condron C, Bouchier-Hayes D. A reduction in serum cytokine levels parallels healing of venous ulcers in patients undergoing compression therapy. Eur J Vasc Endovasc Surg 2002;23(4):349-52.

30. Wong VW, Crawford JD. Vasculogenic cytokines in wound healing. Biomed Res Int 2013;2013:190486.

31. Rissanen TT, Vajanto I, Hiltunen MO, Rutanen J, Kettunen MI, Niemi M, Leppanen P, Turunen MP, Markkanen JE, Arve K, ALhava E, Kauppinen RA, Yla-Herttuala S. Expression of vascular endothelial growth factor and vascular endothelial growth factor receptor-2 (KDR/Flk-1) in ischemic skeletal muscle and its regeneration. Am J Pathol 2002;160(4):1393-403.

32. Dubsky M, Jirkovska A, Bem R, Fejfarova V, Varga M, Kolesar L, Pagacova L, Sykova E, Jude EB. Role of serum levels of angiogenic cytokines in assessment of angiogenesis after stem cell therapy of diabetic patients with critical limb ischemia. Cell Transplantat 2014;23(12):1517-23.

33. Lim YC, Bhatt MP, Kwon MH, Park D, Na S, Kim YM, Ha KS. Proinsulin C-peptide prevents impaired wound healing by activating angiogenesis in diabetes. J Invest Dermatol 2015;135(1):269-78.

34. Jones AG, Hattersley AT. The clinical utility of C-peptide measurement in the care of patients with diabetes. Diabet Med 2013;30(7):803-17.

35. Walcher D, Babiak C, Poletek P, Rosenkranz S, Bach H, Betz S, Durst R, Grub M, Hombach V, Strong J, Marx N. C-Peptide induces vascular smooth muscle cell proliferation: involvement of SRC-kinase, phosphatidylinositol 3-kinase, and extracellular signal-regulated kinase 1/2. Circ Res 2006;99(11):1181-7. 